\title{
Galectin 3: Newest Marker of HF Outcomes
}

\author{
Brian Knight • Yang Xue • Alan S. Maisel • \\ Rudolf A. de Boer
}

Published online: 13 March 2014

(c) Springer Science+Business Media New York 2014

\begin{abstract}
Heart failure is an ever-growing health issue in Western society that affects millions of patients each year. This problem is further exacerbated by high mortality and readmission rates post discharge. Despite recent medical advances, $25 \%$ of patients admitted for heart failure are readmitted within 30 days, and $30 \%$ die within a year. Better risk stratification would decrease such outcomes by identifying patients that require closer follow-up or more aggressive treatment. Galectin-3 is a new heart failure biomarker that has shown great prognostic potential and could aid in such risk stratification. Galectin-3 plays a unique role in the progression of heart failure and is also associated with cardiac remodeling and fibrogenesis, making galectin-3 an effective prognosticator of near and longer term outcomes. This review summarizes the current knowledge about galectin-3 and highlights key studies that demonstrate its prognostic potential. We discuss the potential utility of galectin-3 and suggest that it may be used in conjunction with other heart failure biomarkers. This may provide better risk stratification with the aim of decreasing mortality, healthcare costs, and readmission rates.
\end{abstract}

Keywords Heart failure - Biomarkers · Galectin-3 . Cardiac remodeling

B. Knight · Y. Xue $(\bowtie) \cdot$ A. S. Maisel

Division of Cardiology, University of California San Diego, 9300 Campus Point Drive, La Jolla,

CA 92037-7411, USA

e-mail: yxue100@yahoo.com

R. A. de Boer

Division of Cardiology, University of Groningen, University

Medical Center Groningen, Groningen, Netherlands

\section{Introduction}

Heart failure (HF) is an increasing healthcare challenge in the USA. In the current era of healthcare reform, there is a new emphasis on the quality of care delivered. Short-term HF readmission rates are being used as a metric of the quality of inpatient care for HF patients. This shift largely stemmed from the increasing healthcare burden of $\mathrm{HF}$ management in the US. In the US, we have seen a steady increase in the prevalence and incidence of HF over the past decade. There are almost 6 million patients with HF in the US, with over 600,000 new cases of HF diagnosed each year. Among the elderly, HF is the number one reason for hospitalizations [1]. HF hospitalizations are not only associating with significant mortality and morbidity, but also account for almost half of the cost associated with HF [2]. Up to $25 \%$ of patients hospitalized for HF are readmitted within 30 days, and $30 \%$ die within 1 year of the index HF admission [3, 4]. There is a pressing need for better risk stratification and novel therapies to reduce the cost effectiveness and the treatment outcomes of HF patients. As HF is a complex disease process, a multifaceted approach is required to improve treatment outcomes. While strategies to improve compliance with the guidelines-recommended therapies, improve patient education, and intense outpatient therapy have resulted in a moderate degree of success, it is becoming increasingly clear that an individualized approach is required to significantly improve outcomes [5, 6]. An individualized approach for HF management hinges on accurate prognostic evaluation and tailored therapies based on an individual's risk. Biomarkers representing different pathophysiological processes can be very valuable additions to traditional risk stratification models by providing an individualized risk profile to help clinicians to direct resources to patients at high risk for adverse outcomes. 


\section{Galectin-3 and the Pathophysiology of Heart Failure}

Galectin-3 is a $29-35-\mathrm{kDa}$ member of the galectin family, a class of proteins defined by their ability to bind $\beta$ galactosides via a highly conserved carbohydrate recognition domain (CRD). The rest of the galectin structure consists of a proline- and glycine-rich $\mathrm{N}$-terminal domain that enables galectin-3 to form oligomers. Galectin-3 is expressed in tissues throughout the body and has been attributed roles in various biological processes, including development, the immune response and inflammation, tissue repair, and the progression of cancer [7]. Within the cell, galectin-3 regulates apoptosis and the cell cycle [8], whereas outside the cell galectin- 3 has been associated with cell activation, migration, and cell adhesion and interaction. Plasma levels of galectin-3 can be measured with an FDA-approved, enzyme-linked, immune-sorbent assay $[9,10]$.

When the heart is stressed or injured, several cells, including neutrophils, monocytes, macrophages, and mast cells, hone to the sites of injury. These macrophages are a major source of galectin-3. In the cardiac tissue of heart failure patients, the increased expression of galectin-3 causes fibroblast activation. This causes the fibroblasts to dedifferentiate into myofibroblasts, which produce and secrete collagens that deposit in the heart, ultimately resulting in cardiac fibrosis. Galectin-3 may modulate the inflammatory response of the damaged cardiac tissue during early stage HF; however, in the long term, it adds to prolonged and progressive tissue changes, most strikingly fibrogenesis. This pathophysiological role of galectin-3 in heart failure has been confirmed in animal models. Rats with recombinant galectin-3 pericardial infusion had increased fibroblast proliferation, collagen deposition, and decreased cardiac function [11••], while galectin-3 knockout mice exhibited less fibrosis and better echocardiographic parameters of cardiac function when perturbed with pressure overload [12•]. Galectin-3 was also found to be the most overexpressed gene in failing compared to healthy hearts, and high galectin-3 levels at an early time point identified rats with hearts that were predisposed to failure [11••]. Underscoring the central role of galectin-3 in fibrosis, it has been shown to correlate with PIIINP, MMP-2, and TIMP-1, which are markers of extracellular matrix (ECM) turnover in the myocardium [13]. ECM turnover is a process that is important in LV remodeling and cardiac fibrosis, which further supports that galectin-3 plays a major role in the progression of heart failure [14].

This chapter will describe the utility of galectin-3 as an adjunct in heart failure risk assessment and stratification, with an emphasis on acute heart failure.

\section{Galectin-3 in the Prediction of Heart Failure}

By hitherto unexplained mechanisms, galectin-3 is secreted into the circulation and can be reliably measured with an FDA-approved ELISA [9, 10]. All studies described here reported galectin-3 results measured by this assay.

Galectin-3 can be used in a clinical setting to predict a patient's risk of developing heart failure long before symptoms of failure present (Fig. 1). Galectin-3 is also associated with clinical risk factors for HF, including age, NYHA class, and VO2 max. Additionally, galectin-3 has been correlated with other heart failure biomarkers, such as b-type natriuretic peptide (BNP), amino terminal prohormone B-type natriuretic peptide (NT-proBNP), and C-reactive protein [15].

Given the described role of galectin- 3 in myocardial fibrosis, it has been put forward that long-term elevations in galectin-3 might precede the development of cardiovascular disease and mortality.

Several observations have provided evidence for this hypothesis. In ACS patients from the PROVE IT-TIMI 22 trial, higher baseline galectin-3 levels showed a graded association with the risk of developing heart failure. In a nested case-control study, patients who developed heart failure following hospitalization for ACS had significantly higher baseline galectin-3 levels $($ median $=16.7 \mathrm{ng} / \mathrm{ml})$ compared to ACS patients who did not develop HF $($ median $=14.6 \mathrm{ng} / \mathrm{ml})$. After adjustment for prior HF, prior MI, diabetes, and hypertension, this association remained significant [16].

Galectin-3 has also been studied in the general population. The first study to report this was the PREVEND study [17]. Of 7,968 patients enrolled, 614 subjects $(7.7 \%)$ died over the course of 10 years. Galectin-3 correlated with almost all cardiovascular risk factors, although the total model could only explain $\sim 20 \%$ of the variation in galectin-3 levels. Galectin-3 significantly predicted allcause mortality-patients in the highest quintile were threefold more likely to die compared to subjects in the lowest quintile. Galectin-3 also remained a significant predictor for mortality after correction for the Framingham risk score: per SD increase in galectin-3, there was a $9 \%$ increase in the risk for mortality. A second study described 3,353 Framingham Heart Study participants also followed up for approximately 10 years. A 1-SD increase in galectin-3 level was associated with a $28 \%$ higher risk of developing incident heart failure, and this association remained significant even after adjustment for B-type natriuretic peptide and other clinical variables. Furthermore, this study found galectin-3 was significantly associated with all-cause mortality; per SD increase in galectin3 there was a $14 \%$ increase in the risk for mortality [18•]. 
Fig. 1 Galectin-3-mediated HF is inherently progressive. Illustration of two imaginary, clinically very similar patients, with substantially different galectin-3 levels and dramatically different clinical paths as a result

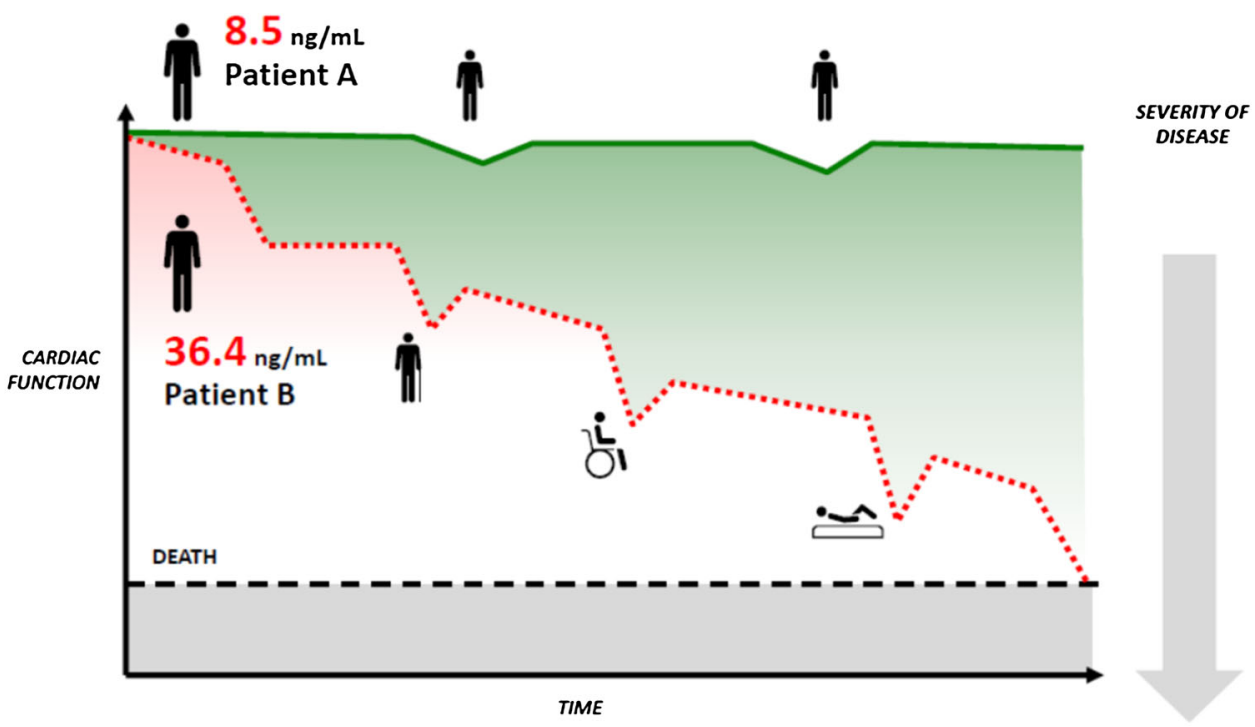

The experimental data showing the pivotal role for galectin-3 in fibrogenesis and the epidemiological data showing that elevated galectin-3 precedes the onset of various fibrotic diseases have prompted the hypothesis that galectin-3 is not only a marker, but also a mediator of diseases such as heart failure.

\section{Galectin-3 and Near Term Prognosis of Heart Failure}

Galectin-3 is not only a predictor for developing incident heart failure, clinical studies have extensively proven galectin-3 is also a strong prognosticator of adverse outcomes in patients with prevalent heart failure (Table 1). This information could aid clinicians in identifying patients with poor prognosis, who may require closer follow-up, intensified pharmacological or non-pharmacological treatment, or counseling.

In acute heart failure patients from the Pro-BNP Investigation of Dyspnea in the Emergency Department (PRIDE) study, higher galectin-3 levels were associated with significantly increased risk of mortality at 60-day follow-up when compared to lower galectin-3 levels (12.9-16.5 vs. $9.0-11.6 \mathrm{ng} / \mathrm{ml}, p<0.001)$. In a multivariate analysis, the study also found galectin-3 levels predicted adverse events at 60 days with the combined endpoint of death or recurrent HF (OR 14.3, $p<0.001$ ). Galectin-3 also was a better predictor of mortality within 60 days than NT-proBNP, with an AUC of 0.74 versus 0.67 [19•]. An unpublished analysis by de Boer et al. [20], which pooled heart failure patients enrolled in the Coordinating Study Evaluating Outcomes of Advising and Counseling in Heart Failure (COACH, $n=892$ ), PRIDE $(n=181)$, and University of Maryland Pro-BNP for Diagnosis and Prognosis in Patients Presenting with
Dyspnea studies $(n=129)$, confirmed the potential utility of galectin-3 as a prognosticator of near term outcome. Patients with galectin-3 levels above $17.8 \mathrm{ng} / \mathrm{ml}$ were 2.8 times more likely to have an $\mathrm{HF}$ readmission within 30 days of discharge $(p<0.01)$ and 3.0 times more likely to be admitted for HF within 90 day post-discharge $(p<0.01)$. Galectin-3 remained a significant predictor of readmission after adjustment for age, NYHA class, gender, renal function, left ventricular ejection fraction (LVEF), and (NT-pro) BNP levels.

\section{Galectin-3 and Long Term Prognosis of Heart Failure}

In a substudy of the $\mathrm{COACH}$ trial, which followed 592 patients admitted for HF for 18 months, patients with elevated galectin-3 levels (the fourth quartile, $25.9-66.6 \mathrm{ng} / \mathrm{ml}$ ) had a higher risk of death or heart failure readmission within 18 months post discharge when compared to the lowest quartile (the first quartile, $5.0-15.2 \mathrm{ng} /$ ml) (HR 3.34, $95 \%$ CI 2.23-5.01, $p<0.001$ ). After adjustment for age, gender, and BNP, galectin-3 remained a strong prognosticator of HF admission or all-cause mortality at 18 months $[21 \bullet]$.

During a 6.5-year follow-up study that enrolled 232 chronic heart failure patients from the Deventer-Alkmaar Heart Failure (DEAL-HF) study, galectin-3 was an independent predictor of mortality after adjustment for age, sex, severity of HF, and renal dysfunction (hazard ratio per standard deviation $=1.24, p=0.026$ ) [15].

Several other post hoc analyses from large-scale randomized trials have confirmed that galectin-3 is a strong prognosticator for outcome in chronic heart failure [22-24]. Several of these studies reported a strong interaction between galectin-3 and renal function in the prediction 
Table 1 Key studies reporting on galectin-3 prognostication in heart failure patients

\begin{tabular}{|c|c|c|c|c|c|c|}
\hline Study & $\begin{array}{l}\text { Heart failure } \\
\text { population }\end{array}$ & $\begin{array}{l}\text { Median } \\
\text { gal-3 } \\
(\mathrm{ng} / \mathrm{ml})\end{array}$ & HR & Hazard & $\begin{array}{l}\text { Follow-up } \\
\text { interval }\end{array}$ & With respect to \\
\hline \multicolumn{7}{|c|}{ Gal-3 prognostication of baseline samples } \\
\hline \multirow[t]{2}{*}{ PRIDE [19] } & $\begin{array}{l}\text { Acute HF patients } \\
\quad(n=181)\end{array}$ & $\begin{array}{l}16.5 \\
(\text { mean })\end{array}$ & $\begin{array}{l}10.3 \\
(p<0.01)\end{array}$ & Mortality & 60 days & Gal-3 level > cutoff (multivariate) \\
\hline & & & $\begin{array}{l}14.3 \\
\quad(p<0.001)\end{array}$ & $\begin{array}{l}\text { Mortality or } \\
\text { recurrent } \mathrm{HF}\end{array}$ & 60 days & Gal-3 level > cutoff (multivariate) \\
\hline $\begin{array}{l}\text { DEAL-HF } \\
{[15]}\end{array}$ & $\begin{array}{l}\text { Chronic HF Patients } \\
\quad(n=232)\end{array}$ & $\begin{array}{l}17.7 \\
\text { (cutoff } \\
\text { value) }\end{array}$ & $\begin{array}{l}1.24 \\
\quad(p=0.026)\end{array}$ & Mortality & 6.5 years & Per SD gal-3 (multivariate) \\
\hline $\begin{array}{l}\mathrm{COACH} \\
{[21]}\end{array}$ & $\begin{array}{l}\text { Patients with preserved } \\
\text { and reduced LVEF } \\
(n=592)\end{array}$ & 20.0 & $\begin{array}{l}3.34 \\
\quad(p<0.001)\end{array}$ & $\begin{array}{l}\text { Mortality or } \\
\text { HF- } \\
\text { hospitalization }\end{array}$ & 18 months & $\begin{array}{l}\text { Highest quartile gal-3 vs. lowest quartile } \\
\text { gal-3 (univariate) }\end{array}$ \\
\hline \multirow[t]{2}{*}{$\begin{array}{l}\text { CORONA } \\
{[23]}\end{array}$} & $\begin{array}{l}\text { Chronic, ischemic HF } \\
\text { patients }(n=1,462)\end{array}$ & NA & $\begin{array}{l}2.58 \\
\quad(p<0.001)\end{array}$ & $\begin{array}{l}\text { Mortality } \\
\quad \text { (unadjusted) }\end{array}$ & 32.8 months & $\begin{array}{l}\text { Continuous (Cox proportional hazards } \\
\text { model, univariate) }\end{array}$ \\
\hline & & & $\begin{array}{l}1.68 \\
\quad(p<0.001)\end{array}$ & $\begin{array}{l}\text { CV } \\
\text { hospitalization }\end{array}$ & 32.8 months & $\begin{array}{l}\text { Continuous (Cox proportional hazards } \\
\text { model, univariate) }\end{array}$ \\
\hline $\begin{array}{l}\text { CARE-HF } \\
{[27]}\end{array}$ & $\begin{array}{l}\text { Systolic HF patients } \\
\quad(\mathrm{n}=194)\end{array}$ & $\begin{array}{l}30.0 \\
\text { (cutoff } \\
\text { value) }\end{array}$ & $\begin{array}{l}2.98 \\
\qquad(p=0.004)\end{array}$ & $\begin{array}{l}\text { Death or HF- } \\
\text { hospitalization }\end{array}$ & 18 months & Gal-3 level > cutoff (multivariate) \\
\hline $\begin{array}{l}\text { Tang et al. } \\
\text { [22] }\end{array}$ & $\begin{array}{l}\text { Chronic, systolic HF } \\
\text { patients }(\mathrm{n}=133)\end{array}$ & 13.9 & $\begin{array}{l}1.94 \\
\quad(p=0.001)\end{array}$ & Mortality & 5 years & Per 1 SD increment (multivariate) \\
\hline $\begin{array}{l}\text { HF- } \\
\text { ACTION } \\
{[37]}\end{array}$ & $\begin{array}{l}\text { Chronic, systolic HF } \\
\text { patients }(\mathrm{n}=895)\end{array}$ & 14.0 & $\begin{array}{l}1.05 \\
\quad(p=0.07)\end{array}$ & $\begin{array}{l}\text { Mortality or } \\
\text { hospitalization }\end{array}$ & 2.5 years & $\begin{array}{l}\text { Per } 3 \mathrm{ng} / \mathrm{ml} \text { increase in gal-3 } \\
\text { (multivariate) }\end{array}$ \\
\hline $\begin{array}{l}\text { Carrasco- } \\
\text { Sánchez } \\
\text { et al. [38] }\end{array}$ & $\begin{array}{l}\text { Preserved LVEF HF } \\
\text { patients }(\mathrm{n}=419)\end{array}$ & 13.8 & $\begin{array}{l}1.46 \\
\quad(p=0.04)\end{array}$ & Mortality & 1 year & Gal-3 level above median (multivariate) \\
\hline $\begin{array}{l}\text { Bayes- } \\
\text { Genius } \\
\text { et al. [39] }\end{array}$ & $\begin{array}{l}\text { Mixed heart failure } \\
\text { types }(\mathrm{n}=876)\end{array}$ & 16.5 & $\begin{array}{l}1.39 \\
\quad(p=0.017)\end{array}$ & $\begin{array}{l}\text { Mortality or } \\
\text { HF- } \\
\text { hospitalization }\end{array}$ & 5 years & $\begin{array}{l}\text { Continuous (Cox proportional hazards } \\
\text { model, multivariate) }\end{array}$ \\
\hline \multicolumn{7}{|c|}{ Gal-3 prognostication upon serial sampling } \\
\hline \multirow[t]{2}{*}{$\begin{array}{l}\text { Val-HeFT } \\
{[24]}\end{array}$} & $\begin{array}{l}\text { Mixed heart failure } \\
\text { types }(n=1,063)\end{array}$ & 16.2 & $\begin{array}{l}1.029 \\
(p=0.008)\end{array}$ & Mortality & 32.8 months & $\begin{array}{l}\text { Increase in } 1 \mathrm{ng} / \mathrm{ml} \text { gal- } 3 \text { from baseline to } \\
4 \text { months (multivariate) }\end{array}$ \\
\hline & & & $\begin{array}{l}1.022 \\
\quad(p=0.07)\end{array}$ & $\begin{array}{l}\text { HF- } \\
\text { hospitalization }\end{array}$ & 32.8 months & $\begin{array}{l}\text { Increase in } 1 \mathrm{ng} / \mathrm{ml} \text { gal- } 3 \text { from baseline to } \\
4 \text { months (multivariate) }\end{array}$ \\
\hline $\begin{array}{l}\text { CORONA } \\
{[28]}\end{array}$ & $\begin{array}{l}\text { Chronic ischemic HF } \\
\quad(n=1,329)\end{array}$ & $\begin{array}{l}17.8 \\
\text { (cutoff } \\
\text { value) }\end{array}$ & $\begin{array}{l}1.6 \\
(p=0.007)\end{array}$ & $\begin{array}{l}\text { Mortality or } \\
\text { HF- } \\
\text { hospitalization }\end{array}$ & $3-6$ months & $\begin{array}{l}\text { Increase from low to high gal- } 3 \text { category } \\
\text { on serial measurement baseline to } \\
3 \text { months (multivariate) }\end{array}$ \\
\hline $\begin{array}{l}\mathrm{COACH} \\
{[28]}\end{array}$ & $\begin{array}{l}\text { Acutely } \\
\text { decompensated } \\
\text { patients with HF } \\
(n=324)\end{array}$ & $\begin{array}{l}17.8 \\
\text { (cutoff } \\
\text { value) }\end{array}$ & $\begin{array}{l}2.38 \\
\quad(p=0.046)\end{array}$ & $\begin{array}{l}\text { Mortality or } \\
\text { HF- } \\
\text { hospitalization }\end{array}$ & $3-6$ months & $\begin{array}{l}\text { Increase from low to high gal-3 category } \\
\text { on serial measurement baseline to } \\
6 \text { months (multivariate) }\end{array}$ \\
\hline $\begin{array}{l}\text { PROTECT } \\
\text { [29] }\end{array}$ & $\begin{array}{l}\text { LV systolic } \\
\text { dysfunction } \\
(n=145)\end{array}$ & 20.0 & $\begin{array}{l}2.85 \\
\quad(p=0.03)\end{array}$ & CV event & 3 months & $\begin{array}{l}\text { Increase of } \geq 15 \% \text { in gal- } 3 \text { over } 3 \text { months } \\
\text { serial sampling (univariate) }\end{array}$ \\
\hline
\end{tabular}

models of mortality and $\mathrm{HF}$ rehospitalization. Since the published effects of galectin-3 on renal fibrosis and the observation that elevated galectin-3 precedes chronic kidney disease in the general population [25], this interaction comes as no surprise. However, the precise relation between galectin-3 and renal function remains incompletely understood, and mechanistic studies should clarify this nature.
Mechanistically, higher galectin-3 levels have also been associated with LV systolic and diastolic function. A substudy describing 115 patients from the PRIDE study showed that galectin-3 was associated with echocardiographic parameters representative of altered or impaired cardiac function, including the tissue Doppler E/Ea ratio, lower RV fractional area change, higher RV systolic 
pressure, and more severe mitral or tricuspid regurgitation. Additionally, among those patients that were ultimately diagnosed with acutely decompensated heart failure, the galectin-3 level was an independent predictor of mortality 4 years from baseline. Interestingly, the prognostic ability of galectin-3 was independent of echocardiographic parameters of cardiac dysfunction [26]. Furthermore, a substudy from the DEAL study showed that elevated galectin-3 was associated with unfavorable LV remodeling assessed with echo [15].

\section{Serial Sampling of Galectin-3}

Since elevated galectin-3 may not only detect but also contribute to tissue fibrosis and progressive cardiac remodeling, it seems reasonable to serially measure galectin-3 in an effort to monitor disease progression. Indeed, three recent studies have found that serial sampling of galectin-3 does provide additional prognostic value [27, 28]. First, van der Velde et al. described that in the CORONA and COACH studies, comprised of patients with ambulatory and acutely decompensated HF, respectively, serial sampling provides strong prognostic power, even stronger than baseline values alone. Specifically, it was shown that an increase of $15 \%$ or more (this \% was chosen based on the CV value of the galectin-3 assay, which is around $7 \%$, and because of reasons of power optimization) is associated with an up to $50 \%$ worse outcome (all-cause mortality and HF rehospitalization). Likewise, in a secondary analysis, patients that "changed lanes," i.e., had $<17.8 \mathrm{ng} / \mathrm{ml}$ at baseline but $>17.8 \mathrm{ng} / \mathrm{ml}$ at follow-up, had a markedly worse outcome when compared to patients that had levels $<17.8 \mathrm{ng} / \mathrm{ml}$ at both time points, and even better than the ones that were initially high, but low at follow-up [23]. Additionally, in a substudy from the VaLHeFT study, each $1 \mathrm{ng} / \mathrm{ml}$ rise in the galectin3 level at 4 months was correlated with a $2.9 \%$ higher risk of mortality $(p=0.008)$ and a $2.2 \%$ greater risk in heart failure hospitalization ( $p=0.07)$ [24]. Finally, in a substudy of the PROTECT study, it was confirmed that galectin-3 levels vary over time: in diastolic HF patients, galectin-3 values were found to vary as much as $35 \%$ within individuals over 3 or 6 months from baseline. Furthermore, galectin-3 measurements taken at 6 months greatly increased the prognostic value from that of the baseline value alone $(p=0.02)$. Patients with galectin-3 levels that stayed low or decreased upon serial sampling had much better prognoses; conversely, an increase in galectin-3 level $\geq 15 \% 3$ months after baseline indicated a much higher risk of a cardiovascular event (OR 2.85, $p=0.03$ ) [29].

\section{Galectin-3 with Natriuretic Peptides}

Nowadays, much attention is given to the potential utility of multimarker approaches, where different markers may detect different disease phenomena and domains, with a composite score that provides caring physicians with superior information about the patient. This may be especially useful regarding heart failure patients because within the entire heart failure population, there are different subgroups that vary substantially with respect to etiology of heart failure and presence of comorbidities. With this diversity in heart failure patients, a multimarker approach utilizing different biomarkers, each representing a unique pathophysiological processes, may result in better risk stratification. The best established heart failure biomarkers are natriuretic peptides (NPs). NPs are biomarkers of myocardial stretch and strain, and as such they become elevated in patients with acute heart failure. NPs are widely used to diagnose HF among patients presenting with acute dyspnea; however, they are also powerful predictors of prognosis in heart failure. Combined use of galectin-3 and NPs could provide additional aid in determining prognosis by providing information about different "domains," i.e., fibrosis (galectin-3) and myocardial wall stretch (NPs).

Several studies have illustrated the incremental prognostic value of adding galectin-3 to NPs. In the PRIDE study, patients with high galectin-3 and NT-proBNP had significantly worse prognosis than those with only high NT-proBNP levels or only galectin-3 [19•]. The DEAL-HF study also showed that both biomarkers are associated with poor outcome, but the outcome is worst when both markers are elevated. Patients with high (above median) NTproBNP levels and low (below median) galectin-3 levels had a $34.7 \%$ risk of mortality, while this increased to a $56.1 \%$ chance of death for patients who had galectin-3 and NT-proBNP levels that were higher than the median values [15]. In HF patients from the $\mathrm{COACH}$ trial, BNP and galectin-3 predicted death or HF readmission at 18-month follow-up with AUCs of 0.65 and 0.67, respectively. Combining both biomarkers, however, resulted in increased prognostic power with an AUC of 0.69 $(p<0.05)$ [21•]. Currently, there are several studies underway that describe the potential utility of the "multimarker" approach in patients at risk for heart failure and in patients with prevalent heart failure.

\section{Galectin-3 and Differential Drug Therapy Response}

Given the well-defined role of galectin-3 in the pathophysiology of $\mathrm{HF}$, and the observation that galectin-3 is elevated in a subset of HF patients, it is interesting to speculate that galectin-3 could be of particular use in 
specific subsets of HF. Therefore, galectin- 3 could potentially identify heart failure patients that may benefit more from certain types of therapy. It was reported that in ischemic heart failure patients from the CORONA trial, galectin-3 identified patients who were more likely to benefit from rosuvastatin treatment. Among patients with galectin-3 levels less than or equal to the median value of $19.0 \mathrm{ng} / \mathrm{ml}$, those treated with rosuvastatin had a $30.4 \%$ reduction in $\mathrm{CV}$ death, non-fatal MI, and non-fatal stroke when compared to those who received placebo $(p=0.036)$. Conversely, patients with levels above the median derived no benefit from the drug [30]. In a substudy of the Val-HeFT trial, galectin-3 similarly predicted whether HF patients benefited from treatment with the ARB valsartan. Patients who were treated with valsartan and had baseline galectin-3 levels below the median had a $46 \%$ reduction in $\mathrm{HF}$ hospitalization as compared to the control group, while valsartan treatment had no positive effect on patients with levels above the cutoff [24]. The possible explanation for the observations in these trials might be that HF patients with severely elevated galectin-3 levels are "beyond repair" and no longer benefit from additional pharmacotherapy, while the ones with lower levels still have active fibrosis and remodeling going on, providing an opportunity for therapy to be act on this. Prospective data are clearly needed to address these hypotheses.

\section{Galectin-3 as a Therapeutic Target}

Fibrosis is a general response of the body, including the heart, to injury. In the heart, however, it is regarded as a maladaptive response since fibrotic heart tissue is characterized by impaired relaxation and contractility, and it represents an arrhythmogenic substrate. Galectin-3 has a central role in fibrogenesis: it activates fibroblasts and stimulates collagen production, but it is also involved in other elementary aspects of fibrogenesis, such as collagen processing, maturation, cross linking, and deposition. Therefore, galectin-3 is an attractive therapeutic target. By decreasing the activity of galectin- 3 in the heart, it may be clinically possible to slow the progression of cardiac fibrosis and ensuing cardiac remodeling and heart failure.

There is accumulating experimental evidence from animal models that it is feasible to inhibit galectin-3. The first study to show that galectin-3 in the heart may be inhibited tested intrapericardial infusion of $\mathrm{N}$-acetyl-serylaspartyl-lysyl-proline (Ac-SDKP), a naturally occurring peptide with anti-inflammatory and antifibrotic properties $[31,32]$. In this study, rats developed cardiac inflammation, fibrosis, and cardiac dysfunction after intrapericardial delivery of galectin-3; however, when AC-SDKP was administered concurrently with galectin-3, these harmful effects were abolished. A second study provided several lines of evidence that inhibition of galectin-3 may protect the heart from adverse remodeling. First, complete genetic disruption of galectin-3 in mice deficient for the gene encoding galectin-3 (galectin-3 KO mice) was shown to lead to less fibrosis and LV dysfunction when they were subjected to pressure overload (transverse aortic constriction, TAC) or infusion of angiotensin II. Furthermore, progression of heart failure in transgenic, HF-prone, Ren-2 rats was halted by treating the rats with $N$-acetyllactosamine (N-Lac), a molecule that inhibits galectin-3 by targeting its carbohydrate recognition domain. Finally, it was shown that in mice who had established cardiac fibrosis (4 weeks after TAC), treatment with $N$-Lac prevented further progression of fibrosis and LV dysfunction, suggesting that targeting of galectin-3 could be beneficial not only in subjects at risk for HF development, but also in subjects with already damaged hearts [12•].

In yet another study, it was demonstrated that galectin-3 also mediates vascular fibrosis in response to high aldosterone. Inhibition of galectin-3 with modified citrus pectin as well as through aldosterone inhibition with spironolactone both effectively inhibited aldosterone-induced vascular inflammation, fibrosis, and remodeling [33].

\section{Summary and 5-Year Outlook}

Galectin-3 is a biomarker of inflammation and fibrosis that is strongly associated with adverse remodeling of the myocardium and subsequent ventricular dysfunction. Galectin-3 levels are elevated long before the onset of symptomatic HF. In HF patients, an elevated galectin-3 level is strongly associated with increased short- and longterm risk for mortality and readmission. With new 30-day readmission-based performance measures in the US, there is a nationwide need to reduce short-term readmission in acute HF patients. As patients who receive early and close outpatient follow-up tend to have fewer readmissions, a significant amount of attention has been placed on early follow-up post-HF admission [34]. However, logistical challenges and limited resources have limited the success of this approach. As a result, many high-risk HF patients enter into a cycle of repeated short-term readmission and increased risk for adverse outcomes. If we can improve the risk stratification of patients at the time of discharge, efforts can be made to ensure high-risk patients receive adequate outpatient follow-up in order to prevent costly readmission. A combination of clinical risk factors and highly prognostic biomarkers representing different pathophysiological processes is likely required to improve the risk stratification at the time of discharge. Galectin-3 is a potent biomarker of fibrosis. It can be an excellent adjunct to other highly 
prognostic biomarkers, such as NPs. Patients with low galectin-3 levels and a significant reduction in NP levels during hospitalization (more than $50 \%$ reduction) or low discharge NP levels (BNP $<400 \mathrm{pg} / \mathrm{ml}$ or NT-proB$\mathrm{NP}<1,800 \mathrm{pg} / \mathrm{ml}$ ) are at low risk for short-term readmission. They can be safely triaged to routine follow-up, while patients with high galectin-3 levels or high NP levels on discharge should receive intensive outpatient follow-up. At the first post-discharge follow-up appointment, patients who appear congested or have uptrending NP levels should be followed closely to avoid short-term readmissions. On the other hand, patients who appear euvolemic with downtrending NP levels at the post-discharge follow-up visit are at low risk for readmission. These patients should be considered for routine follow-up. Patients with high galectin-3 levels and high NP levels on discharge are at the highest risk for short- and long-term adverse outcomes. These patients should be followed closely and receive aggressive medical management.

An often overlooked area to reduce short-term HF readmissions is the emergency department (ED). Better risk stratification of patients presenting to the ED with acute HF symptoms can have a substantial impact on reducing HF readmissions. Up to $80 \%$ of patients presenting to the ED with acute HF are routinely admitted to the hospital $[35,36]$. Many of these admissions may be preventable if low-risk patients can be correctly identified. Low-risk patients can often be treated and observed in the ED. Biomarkers such as galectin-3 and NP can be quite useful in this setting. Patients with low galectin-3 levels and low NP levels should be considered for discharge from the ED if they respond well to initial HF therapy. Patients with low galectin-3 levels and elevated NP levels can still be considered for discharge if they respond to therapy and demonstrate decreasing NP levels on serial measurement. Finally, patients with high galectin-3 and high NP levels should receive prompt therapy in the ED and be considered for readmission because of their high risk for short-term adverse outcomes.

\section{Summary}

In the current era of healthcare reform, increasing attention is being paid to the quality of care delivered. One of the new metrics of HF management in the US is the rate of short-term readmissions. Many of these costly readmissions can be prevented if high-risk patients are correctly identified and receive appropriate outpatient follow-up. Appropriate ED triage of low-risk patients to ED-based therapy and observation can also help to reduce HF readmissions. Galectin-3 is a biomarker of fibrosis that is strongly associated with adverse outcomes in HF patients.
Given the presently available evidence, it can be considered to include galectin-3 in future risk stratification strategies to identify high-risk patients who would benefit from close outpatient follow-up and low-risk patients who can be safely discharged from the ED. This individualized approach based on clinical risk factors and biomarkers has the potential to optimize resource allocation and improve the overall treatment outcomes of HF patients.

\section{Compliance with Ethics Guidelines}

Conflict of Interest BG Medicine, Inc. (BGM, Waltham, MA, USA), holds certain rights with respect to the use of galectin-3 in heart failure. Dr. Xue received an honorarium and travel grant from BGM, and Drs. de Boer and Maisel received consultancy fees from BGM. The UMCG, Department of Cardiology, which employs Dr. de Boer, received research grants from BGM. Dr. Knight has nothing to disclose.

Human and Animal Rights and Informed Consent This article does not contain any studies with human or animal subjects performed by any of the authors.

\section{References}

Recently published papers of particular interest have been highlighted as:

- Of importance

•• Of major importance

1. Lloyd-Jones D, Adams RJ, Brown TM, et al. Heart disease and stroke statistics-2010 update a report from the american heart association. Circulation. 2010;121(7):e46-215.

2. Yu W, Ravelo A, Wagner TH, et al. Prevalence and costs of chronic conditions in the VA health care system. Med Care Res Rev. 2003;60(3 Suppl):146S-67S.

3. Bueno H, Ross JS, Wang Y, et al. Trends in length of stay and short-term outcomes among medicare patients hospitalized for heart failure, 1993-2006. JAMA. 2010;303(21):2141-7.

4. Dharmarajan K, Hsieh AF, Lin Z, et al. Diagnoses and timing of 30-day readmissions after hospitalization for heart failure, acute myocardial infarction, or pneumonia heart failure, acute MI, or pneumonia readmissions. JAMA. 2013;309(4):355-63.

5. Hernandez AF, Hammill BG, Peterson ED, et al. Relationships between emerging measures of heart failure processes of care and clinical outcomes. Am Heart J. 2010;159(3):406-13.

6. Chaudhry SI, Mattera JA, Curtis JP, et al. Telemonitoring in patients with heart failure. N Engl J Med. 2010;363(24):2301-9.

7. Dumic J, Dabelic S, Flogel M. Galectin-3: an open-ended story. Biochim Biophys Acta. 2006;1760(4):616-35.

8. Kim HR, Lin HM, Biliran H, Raz A. Cell cycle arrest and inhibition of anoikis by galectin-3 in human breast epithelial cells. Cancer Res. 1999;59(16):4148-54.

9. Christenson RH, Duh SH, Wu AH, et al. Multi-center determination of galectin-3 assay performance characteristics: anatomy of a novel assay for use in heart failure. Clin Biochem. 2010;43(7-8):683-90.

10. Meijers WC, de Boer RA. The ARCHITECT, automated and manual diagnostic assays for the measurement of galectin-3. Exp Rev Mol Diagn 2013 (in press). 
11. • Sharma UC, Pokharel S, van Brakel TJ, et al. Galectin-3 marks activated macrophages in failure-prone hypertrophied hearts and contributes to cardiac dysfunction. Circulation. 2004;110(19): 3121-28. The first study that identified the relation between galectin-3 and heart failure.

12. - Yu L, Ruifrok WP, Meissner M, et al. Genetic and pharmacological inhibition of galectin-3 prevents cardiac remodeling by interfering with myocardial fibrogenesis. Circ Heart Fail. 2013;6(1):107-17. This study provides several lines of evidence that inhibition of galectin-3 attenuates heart failure development, and thus is not only a marker of disease.

13. Lin YH, Lin LY, Wu YW, et al. The relationship between serum galectin-3 and serum markers of cardiac extracellular matrix turnover in heart failure patients. Clin Chim Acta. 2009; 409(1-2):96-9.

14. Graham HK, Horn M, Trafford AW. Extracellular matrix profiles in the progression to heart failure. European young physiologists symposium keynote lecture-bratislava 2007. Acta Physiol (Oxf). 2008;194(1):3-21.

15. Lok DJ, Van Der Meer P, de la Porte PW, et al. Prognostic value of galectin-3, a novel marker of fibrosis, in patients with chronic heart failure: data from the DEAL-HF study. Clin Res Cardiol. 2010;99(5):323-8.

16. Grandin EW, Jarolim P, Murphy SA, et al. Galectin-3 and the development of heart failure after acute coronary syndrome: pilot experience from PROVE IT-TIMI 22. Clin Chem. 2012;58(1): 267-73.

17. de Boer RA, van Veldhuisen DJ, Gansevoort RT, et al. The fibrosis marker galectin-3 and outcome in the general population. J Intern Med. 2012;272(1):55-64.

18. - Ho JE, Liu C, Lyass A, et al. Galectin-3, a marker of cardiac fibrosis, predicts incident heart failure in the community. J Am Coll Cardiol. 2012;60(14):1249-56. This study showed that elevated galectin-3 levels in subjects without apparent cardiovascular disease precede heart failure development.

19. • van Kimmenade RR, Januzzi JL Jr, Ellinor PT, et al. Utility of amino-terminal pro-brain natriuretic peptide, galectin-3, and apelin for the evaluation of patients with acute heart failure. J Am Coll Cardiol. 2006;48(6):1217-24. First study to describe the prognostic value of galectin-3 in clinical heart failure.

20. de Boer RA, van Veldhuisen DJ, de Filippi C, et al. Plasma galectin-3 is associated with near-term rehospitalization in heart failure: a meta-analysis. J Card Fail. 2011;17(8):93.

21. - de Boer RA, Lok DJ, Jaarsma T, et al. Predictive value of plasma galectin-3 levels in heart failure with reduced and preserved ejection fraction. Ann Med. 2011;43(1):60-68. This study describes the value of galectin-3 in a large cohort of patients with heart failure, particularly heart failure with a preserved ejection fraction.

22. Tang WH, Shrestha K, Shao Z, et al. Usefulness of plasma galectin-3 levels in systolic heart failure to predict renal insufficiency and survival. Am J Cardiol. 2011;108(3):385-90.

23. Gullestad L, Ueland T, Kjekshus J, et al. The predictive value of galectin-3 for mortality and cardiovascular events in the controlled rosuvastatin multinational trial in heart failure (CORONA). Am Heart J. 2012;164(6):878-83.

24. Anand IS, Rector TS, Kuskowski M, Adourian A, Muntendam P, Cohn JN. Baseline and serial measurements of galectin-3 in patients with heart failure: relationship to prognosis and effect of treatment with valsartan in the val-HeFT. Eur J Heart Fail. 2013;15(5):511-8.

25. O'Seaghdha CM, Hwang SJ, Ho JE, Vasan RS, Levy D, Fox CS. Elevated galectin-3 precedes the development of CKD. J Am Soc Nephrol. 2013;24(9):1470-7.

26. Shah RV, Chen-Tournoux AA, Picard MH, van Kimmenade RR, Januzzi JL. Galectin-3, cardiac structure and function, and longterm mortality in patients with acutely decompensated heart failure. Eur J Heart Fail. 2010;12(8):826-32.

27. Lopez-Andres N, Rossignol P, Iraqi W, et al. Association of galectin-3 and fibrosis markers with long-term cardiovascular outcomes in patients with heart failure, left ventricular dysfunction, and dyssynchrony: insights from the CARE-HF (cardiac resynchronization in heart failure) trial. Eur J Heart Fail. 2012;14(1):74-81.

28. van der Velde AR, Gullestad L, Ueland T, et al. Prognostic value of changes in galectin-3 levels over time in patients with heart failure: data from CORONA and $\mathrm{COACH}$. Circ Heart Fail. 2013;6(2):219-26.

29. Motiwala SR, Szymonifka J, Belcher A, et al. Serial measurement of galectin-3 in patients with chronic heart failure: results from the ProBNP outpatient tailored chronic heart failure therapy (PROTECT) study. Eur J Heart Fail. 2013;15(10):1157-63.

30. Gullestad L, Ueland T, Kjekshus J, et al. Galectin-3 predicts response to statin therapy in the controlled rosuvastatin multinational trial in heart failure (CORONA). Eur Heart J. 2012;33(18):2290-6.

31. Liu Y, D'Ambrosio M, Liao T, et al. N-acetyl-seryl-aspartyllysyl-proline prevents cardiac remodeling and dysfunction induced by galectin-3, a mammalian adhesion/growth-regulatory lectin. Am J Physiol Heart Circ Physiol. 2009;296(2):H404-12.

32. Azizi M, Rousseau A, Ezan E, et al. Acute angiotensin-converting enzyme inhibition increases the plasma level of the natural stem cell regulator $N$-acetyl-seryl-aspartyl-lysyl-proline. J Clin Invest. 1996;97(3):839-44.

33. Calvier L, Miana M, Reboul P, et al. Galectin-3 mediates aldosterone-induced vascular fibrosis. Arterioscler Thromb Vasc Biol. 2013;33(1):67-75.

34. Hernandez AF, Greiner MA, Fonarow GC, et al. Relationship between early physician follow-up and 30-day readmission among medicare beneficiaries hospitalized for heart failure. JAMA. 2010;303(17):1716-22.

35. Hugli O, Braun JE, Kim S, Pelletier AJ, Camargo CA Jr. United States emergency department visits for acute decompensated heart failure, 1992 to 2001. Am J Cardiol. 2005;96(11):1537-42.

36. Centers for Disease Control and Prevention. National Hospital Ambulatory Medical Care Survey: 2008 Emergency Department Summary Tables. Atlanta: Office of Information Services; 2008.

37. Felker GM, Fiuzat M, Shaw LK, et al. Galectin-3 in ambulatory patients with heart failure results from the HF-ACTION study. Circulation. 2012;5(1):72-8.

38. Carrasco-Sánchez FJ, Aramburu-Bodas O, Salamanca-Bautista P, et al. Predictive value of serum galectin-3 levels in patients with acute heart failure with preserved ejection fraction. Int J Cardiol. 2013;169:177.

39. Bayes-Genis A, de Antonio M, Vila J, et al. Head-to-head comparison of two myocardial fibrosis biomarkers for long-term heart failure risk stratification: ST2 vs. galectin-3. J Am Coll Cardiol. 2013;63:158. 